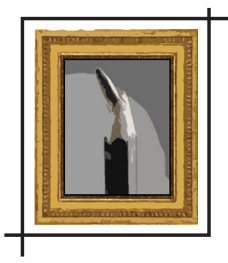

\title{
VIDAS NEGRAS: UM PANORAMA SOBRE OS DADOS DE ENCARCERAMENTO E HOMICÍDIOS DE JOVENS NEGROS NO BRASIL
}

\section{Carolina Bessa Ferreira de Oliveira* \\ Eli Narciso da Silva Torres** \\ Osmar Torres ${ }^{* * *}$}

Resumo: 0 presente artigo tem como objetivo discutir o encarceramento da juventude negra no Brasil. Inicialmente, a partir de um levantamento bibliográfico e dos principais indicadores disponiveis, apresenta o panorama de homicídios e encarceramento de jovens negros no pais para, em seguida, problematizar como os mecanismos de seletividade social operam sobre esse estrato da população com, em especial, recorte etário e racial. Entre os resultados encontrados, sublinha-se que a identificação de suposto "grupo de risco", a ampliação do aprisionamento e o extermínio desses indivíduos negros são reificados socialmente e estão visivelmente imbricados com processo de criminalização das camadas populares moradoras em regiões periféricas. Partindo desses pressupostos, a análise elenca pistas reflexivas sobre como a catalogação social desses homens e dessas mulheres, constituída a priori no inconsciente coletivo, impactam as práticas sistemáticas do sistema de justiça criminal e de seus operadores, e, decisivamente, as trajetórias de vida e também as formas de aplicação da legislação penal. Pode-se notar que os dados da população prisional mais recente, bem como os indicadores de violência letal, apontam para uma sobrerrepresentação do público jovem e negro, o que nos leva a refletir sobre um cenário que tem sido denominado por especialistas de "genocídio da juventude negra" no Brasil, sem que haja uma política específica de enfrentamento a essas práticas sistemáticas.

Palavras-chave: Encarceramento. Juventude negra. Homicídios. Violência. Criminalização da pobreza.

\footnotetext{
* Doutora em Educação pela Universidade de São Paulo (USP). Mestra em Educação pela Universidade Federal de Uberlândia (UFU) e graduada em Direito pela UFU.E-mail: cbessafo@gmail.com

** Doutora em Educação pela Universidade Estadual de Campinas (Unicamp). Mestra em Educação pela Universidade Federal de Mato Grosso do Sul (UFMS) e graduada em Ciências Sociais (UFMS).E-mail: eli.educ@hotmail.com

*** Mestre em Administração pela Universidade Federal de Mato Grosso do Sul (UFMS). Pós-graduado em Direitos Humanos, sistema prisional e execução penal pelo Centro Universitário Filadélfia (Unifil). Graduado em Administração pela Universidade Federal de Mato Grosso do Sul (UFMS).E-mail: osmartor@gmail.com
} 
"Os dados da vitimização juvenil negra, acolhidos com complacência por Estado e sociedade civil, demonstram, nesses termos, o caráter inequivoco da instrumentalização do sistema penal na produção do extermínio desse contingente populacional. Dentro do marco da revolução tecnocientífica, que tende a reconfigurar os termos de sua intervenção, não se observa qualquer possibilidade de arrefecimento, mas, ao contrário, de potencialização da produção da morte em massa" (FLAUZINA, 2006, p. 117).

\section{INTRODUÇÃO}

Os conflitos penitenciários, no Brasil, têm demonstrado o distanciamento da União e dos estados federativos da função de legislar e/ou gerir efetivamente o sistema prisional' e também a constante elevação das taxas de encarceramento.

Pode-se afirmar que o baixo investimento em políticas voltadas às assistências penitenciárias aos presos, previstas na Lei de Execução Penal (LEP), contribuiu para o alargamento da invisibilidade das condições insalubres das prisões e aumento do encarceramento, além de potencializar crescentes conflitos, dentro e fora das prisões, ao longo das últimas décadas no Brasil (TORRES, 2017).

Algumas outras hipóteses foram mobilizadas na literatura especializada para explicar esse crescimento, como a de Dias (2013), para quem o reaparelhamento dos mecanismos repressores do Estado, aliado ao endurecimento da legislação, favoreceu, significativamente, a expansão dos índices de encarceramento.

Entre as alterações legislativas, destaca-se a Lei n. 8.072/1990 que tipificou novos crimes e os introduziu, gradativamente, no rol dos hediondos a partir dos anos 1990. Ademais, a aplicação unilateral da Lei n. 11.343/2006, relacionada ao uso e tráfico de drogas (CAMPOS, 2017), impactou significativamente os indicadores.

Percebe-se que, em certa medida, esses fatos favoreceram o aprisionamento de parcela significativa das 726.712 pessoas no sistema prisional brasileiro², que sustenta a terceira maior população prisional do planeta, precedido apenas por Estados Unidos e China. No âmbito da América do Sul, ocupa o primeiro lugar ${ }^{3}$.

1 - 0 artigo 24 da Constituição Federal de 1988 dispõe que "Compete à União, aos Estados e ao Distrito Federal legislar concorrentemente sobre: [...]" o sistema penitenciário brasileiro. A Constituição Federal limita, em certa medida, os níveis de atuação, intervenção e autonomia da União sobre os estados.

2 - Dado divulgado pelo Departamento Penitenciário Nacional do Ministério da Justiça do Brasil, por meio do Infopen - sistema de informações estatísticas do sistema penitenciário brasileiro, atualizado pelos gestores dos estabelecimentos penais desde 2004. Disponivel em: <http://www.justica.gov.br/news/ha-726-712-pessoas-presas-no-brasil/relatorio_2016_junho.pdf>. Acesso em: 30 de jan. 2018.

3 - Conforme dados também publicados pelo Centro Internacional de Estudos Prisionais (International Centre for Prison Studies - ICPS), do King's College, Londres. Disponivel em: <http://www.prisonstudies.org/>. Acesso em: 5 maio 2016. 
Pode-se afirmar que, apesar de os estudos identificarem o crescimento acentuado do aprisionamento, isso não significou a redução nos índices de violência e criminalidade no país, conforme apontam indicadores ${ }^{4}$ e estudos especializados.

Considerando as complexidades, pesquisas têm se ocupado em investigar, documentar e analisar o sistema de punição no Brasil, nas últimas décadas, sob diferentes prismas. Entre elas, destacam-se, por exemplo, as análises produzidas por Adorno (1991, 1996), Ramalho (1979), Pinheiro (1983), Bitencourt (2017), e outras mais, como Alvarez, Salla e Dias (2013), Salla (2006), Marques (2009). Os estudos convergem no entendimento de que há uma expansão em curso do encarceramento e das violências, em detrimento de investimentos eficientes em políticas públicas e na definição de uma política criminal.

Esses estudos se coadunam com os indicadores de encarceramento e de violências letais divulgados nos mapas da violência (WAISELFISZ, 2012, 2014, 2016), no Atlas da violência (INSTITUTO DE PESOUISA ECONÔMICA APLICADA, 2017) e também no Levantamento Nacional de Informações Penitenciárias do Ministério da Justiça (BRASIL, 2015a, 2017). 0 período 2006 a 2014, por exemplo, demonstra o crescimento massivo do aprisionamento no Brasil e ainda explicita a violência letal contra determinados grupos sociais, sobretudo jovens negros. Essas aproximações demonstram, estatisticamente, que a taxa de encarceramento cresceu $55,1 \%$, em contrapartida ao crescimento populacional de 8,36\%, como mostra o Gráfico 1.

Gráfico 1 Comparativo do crescimento em percentual acumulado entre a população brasileira e de encarcerados (2006-2014)

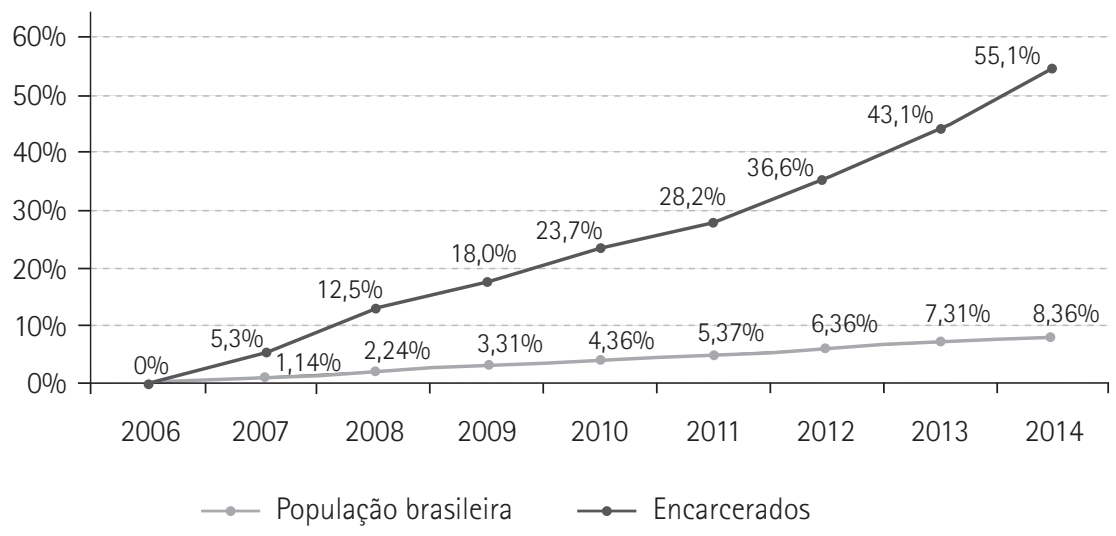

Fonte: Elaborado pelos autores com base em informações disponibilizadas pelo Departamento Penitenciário Nacional (BRASIL, 2015a).

4 - Nesse sentido, por exemplo, ver as publicações e pesquisas divulgadas no Mapa da violência (Faculdade Latino-Americana de Ciências Sociais - Flacso) desde o ano de 1998, que são citadas neste trabalho. Fonte: <http://www.mapadaviolencia.org.br/>. Acesso em: 19 set. 2016. 
Cabe ressaltar que a caracterização do aprisionamento no Brasil aproxima-se, em certa medida, dos estudos de Garland (2001) e Wacquant, (2007, 2011), os quais têm como tônica o foco da punição de jovens e negros e, ainda, crimes específicos, principalmente contra o patrimônio e relacionados ao comércio e uso de drogas.

Nesse sentido, a seletividade penal, seja social, etária ou racial, é conclusão presente tanto para estudiosos internacionais (GARLAND, 2001; WACQUANT, 2007, 2011), como para estudiosos brasileiros (SINHORETTO; SILVESTRE; MELO, 2013; SINHORETTO; SILVESTRE; SCHLITTLER, 2014a, 2014b), ao abordarem as instituições de punição e o encarceramento em massa.

Essa seletividade manifesta-se, subjetivamente, quando as instituições do sistema de punição agem predominantemente focadas em comportamentos ou fenótipos de atores sociais determinados, gerando desigualdades de tratamento nos campos da segurança pública e da justiça criminal. Isso significa que há infrações e parcela de indivíduos que são incluídos a priori em grupos de "suspeitos" em relação a outros estratos da população, neste caso os negros, como observa Flauzina (2006), em condição sine qua non para as forças de segurança. Porém, a seletividade é tácita, sem previsão em lei, mas reificada a todo tempo durante a abordagem policial e seguida na apreciação de mérito pelo sistema de justiça criminal ${ }^{5}$.

Ainda que a aplicação desigual de regras e procedimentos judiciais a indivíduos de diferentes grupos sociais seja um tema recorrente em vários estudos das ciências sociais, são pontuais as pesquisas que analisam a relação entre o encarceramento, a seletividade racial, social e etária no sistema de punição. Apesar da pertinência, observa-se que também são pontuais as análises que contemplam a escalada de violência contra a população jovem e negra identificada pelos índices de violência letal no Brasil.

Nesse ponto, considerando os indicadores de encarceramento e violência estatal, surgem vários debates sobre as causas da violência, e também a necessidade de uma ação governamental, pela via da segurança pública e das políticas públicas, desta vez, que priorize propostas e diretrizes como condição para o exercicio da cidadania, em consonância com o preconizado na legislação constitucional e infraconstitucional vigente.

Entre eles, encontrava-se a proposta de institucionalização do Sistema Único de Segurança Pública (Susp), que na redação inicial, contemplava direcionamentos específicos para políticas de segurança pública e cidadania. 0 projeto de lei aprovou a Lei $n$. 13.675, de 11 de junho de $2018^{6}$ sinaliza a criação de órgão para realizar a gestão unificada de informações e a prevenção da violência entre os eixos norteadores.

\footnotetext{
5 - 0 sistema de justiça criminal contempla a segurança pública, a justiça criminal e a execução penal, sendo constituído por órgãos de diferentes níveis, estadual, municipal e da União, e pelos poderes Judiciário e Executivo.

6 - A legislação "disciplina a organização e o funcionamento dos órgãos responsáveis pela segurança pública, nos termos do $\S 7{ }^{\circ}$ do art. 144 da Constituição Federal; cria a Política Nacional de Segurança Pública e Defesa Social (PNSPDS); institui o Sistema Único de Segurança Pública (Susp); altera a Lei Complementar nº 79, de 7 de janeiro de 1994, a Lei n 10.201, de 14 de fevereiro de 2001, e a Lei $n^{\circ}$ 11.530, de 24 de outubro de 2007; e revoga dispositivos da Lei n 12.681, de 4 de julho de $2012 "$ (BRASIL, 2018).
} 
A iniciativa procura integrar o Susp ao Programa Nacional de Segurança Pública e Cidadania (Pronasci), na direção de mobilizar os mecanismos estatais em busca da prevenção de futuros crimes pela via da política pública, alicerçada, especialmente, no reparo da garantia e respeito dos direitos sociais dos indivíduos em situação de vulnerabilidade, ou seja, que respeitem e promovam a dignidade da pessoa humana.

Porém, como garantir o empoderamento e a dignidade humana pela segurança pública, observando a prevenção da violência, os direitos humanos e sob a égide de um Estado democrático de direito?

Nessa direção, há um paradoxo entre violência e democratização no Brasil, em especial quando se observa que, "nos últimos vinte anos, tanto a violência urbana como a democracia se enraizaram no Brasil sem que uma tenha conseguido ser um freio para outra" (CALDEIRA, 2002, p. 44). A autora prossegue sustentando que o advento da democratização, a partir dos anos 1980, não interferiu nas práticas anteriores, adotadas pelas instituições de controle social, nem as interrompeu: "a polícia e o sistema judiciário têm sido sistematicamente incapazes de garantir à população segurança pública e padrões mínimos de justiça e respeito aos direitos" (CALDEIRA, 2002, p. 44). As frequentes violações de direitos, os homicídios de policiais e cidadãos e os indivíduos vitimados em confrontos policiais no estado do Rio de Janeiro exemplificam as complexidades que envolvem o aparato do sistema de justiça criminal no país.

Assim, por um lado, os pesquisadores de corrente "garantista" pacificam que a dignidade da pessoa humana está relacionada pela viabilidade dos acessos à moradia, ao saneamento e às políticas para jovens, com demandas relacionadas ao esporte, ao lazer e aos bens culturais, que os integrem em período anterior à prisão à sociabilidade da cidade, além dos espaços educativos.

Identifica-se, em certa medida, que ocorre uma articulação entre as forças policiais e as políticas públicas, que se situam, por outro lado, no campo complexo de mediação de conflitos e de interesses na direção de um novo modo de "gestão" de territórios. A linha tênue de uma política dessa natureza será a superação do determinismo que associa o crime, a pobreza e os grupos sociais "minorizados", incluindo neste caso a população negra, a exemplo das políticas de criminalização de populações vulneráveis em países da Europa e dos Estados Unidos e gradativamente exportadas aos países da América Latina, a partir dos anos 1990, como indicou o sociólogo Löic Wacquant, nas obras As prisões da miséria (2011) e Punir os pobres: a nova gestão da miséria nos Estados Unidos (2007).

Esse determinismo que criminaliza o negro, especialmente os jovens e moradores de localidades com altos índices de violência, numa perspectiva de que a periferia produz o suspeito e o criminoso, é importante desafio da segurança pública preventiva e, sobretudo, dos articuladores da defesa dos direitos humanos.

Esse estigma é desconstruído pelo Mapa da violência de 2014, que tratou dos casos relacionados a homicídio e juventude no Brasil, sobretudo porque a análise indica justamente 0 
contrário, isto é, que a população pobre congrega a maior parcela dos individuos vitimados pelos homicídios brasileiros (WAISELFISZ, 2014). Essa população foi caracterizada, pelo estudo, como constituida por pessoas jovens, negras e pobres, restritas aos bairros periféricos de regiões metropolitanas, contabilizando 70\% dos índices de homicidios no país (INSTITUTO DE PESOUISA ECONÔMICA APLICADA, 2014a).

O Relatório Jovens do Brasil também compara a taxa de homicidios entre brancos e negros e a vitimização dos negros no período 2002 a 2012, a cada grupo de 100 mil habitantes, verificando que "O número de homicídios de jovens brancos cai 32,3\%, e dos jovens negros aumenta 32,4\%. As taxas de homicidio de jovens brancos caem 28,6\%; as dos jovens negros aumentam 6,5\%" (INSTITUTO DE PESOUISA ECONÔMICA APLICADA, 2014b, p. 20).

Gráfico 2 Taxas de homicídio e vitimização - população total - Brasil 2002/2012

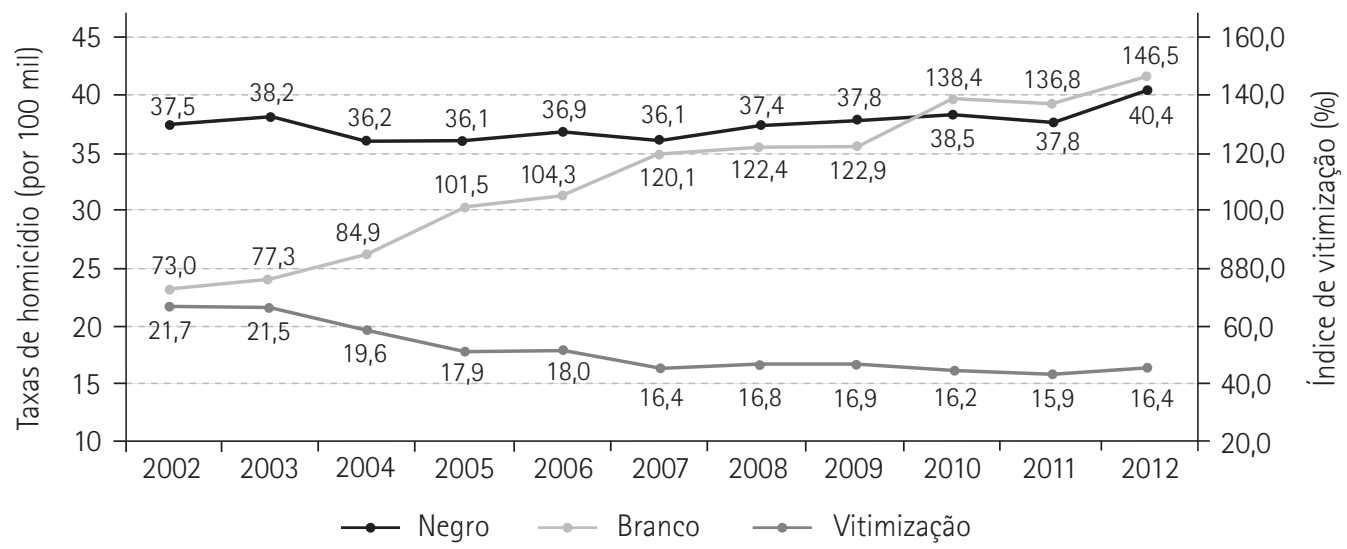

Fonte: Instituto de Pesquisa Econômica Aplicada - IPEA (2014b).

Observa-se que a maior incidência de violência e criminalidade nos espaços periféricos se associa, especialmente, à ausência do Estado e de políticas públicas, por exemplo, com oferta de saúde, educação e cultura. Lopes et al. (2008) alertam que a escassez das características de Estado interventor e/ou apaziguador de desigualdades dá lugar fatalmente no Brasil a medidas mais opressoras da segurança pública a essas comunidades.

Nesse sentido, assemelha-se ao afastamento do Estado da providência social num deslocamento em direção ao Estado penitência, como diz Wacquant (2007, 2011), ao descrever a marginalização dos pobres, latinos e negros na sociedade estadunidense.

Assim, sobrepõe-se o Estado que intervém municiado pelo legalismo jurídico da justiça criminal, que criminaliza condutas e lança mão do aparelhamento penal, com o aprisionamento como mecanismo de gestão da população socialmente vulnerável. 0 afastamento do Estado de suas atribuições na implementação de políticas públicas favorece, também, a gestão do crime organizado nesses territórios, como ocorre em espaços periféricos dos estados 
de São Paulo e do Rio de Janeiro, que há décadas são gerenciados por grupos faccionados ao crime organizado.

\section{PUNITIVISMO, ENCARCERAMENTO E SELETIVIDADE}

0 efeito de endurecer a legislação penal de modo a impactar sobremaneira a elevação dos índices de encarceramento das populações pobres, negras e latinas foi identificado por Wacquant (2007, 2011), entre 1973 e 1996, nos Estados Unidos, como fruto de uma política de reestruturação do Estado, de característica neoliberal.

A análise do contexto refere-se a um gradativo período de diminuição de politicas de assistência social, iniciada nos Estados Unidos e exportada como modelo viável a países da Europa $^{7}$, onde substituiu gradativamente o Estado de bem-estar social por um Estado penal que amplia e massifica as penas e reifica o estigma de uma simbiose entre pobreza e delinquência. Para Wacquant (2007), as políticas penais desenvolvidas no seio da sociedade estadunidense tiveram implicações mundiais que ultrapassaram a clivagem entre crime e castigo, assumindo a missão de instituir novas formas de governo da população submetidas ao processo de desregulamentação e reordenamento econômico.

A flexibilização das responsabilidades do Estado da providência e a transposição para o Estado penitência consagravam-se, naquele período, sob a égide da redução das responsabilidades, tornando-se exemplo para a Europa, pois "A chave da prosperidade norte-americana e a solução para o desemprego de massa residiria numa fórmula simples, para não dizer simplista: menos Estado" (WACQUANT, 2011, p. 85).

Entre as ações, encontravam-se o arrefecimento dos gastos sociais, o enfraquecimento ou a extinção de sindicatos para favorecer a flexibilização das relações de trabalho, o que impactou, inclusive, os direitos individuais do cidadão "via a instauração conjunta de programas de trabalho forçado (work-fare) para os beneficiários de ajuda social" (WACQUANT, 2011, p. 85). Os adeptos das políticas neoliberais, tanto nos Estados Unidos, quanto no Reino Unido e na

\footnotetext{
7 - De acordo com as pesquisas de Löic Wacquant (2007), a Grã-Bretanha foi precursora no acolhimento da política de polícia penal na Europa, que gradativamente se expandiu a outros países, como França, Suécia, Holanda, Espanha e Itália, fato que elevou substancialmente a quantidade de negros, estrangeiros e seus descendentes presos.

8 - Nesse sentido, Wacquant (2007, p. 40-41) observa que "A direção decididamente punitiva tomada pelas políticas penais nas sociedades avançadas no final do século XX não deriva, portanto, do simples 'par crime e castigo'. Ela anuncia a instauração de um novo governo de insegurança social, no sentido amplo de técnicas e procedimentos destinados a dirigir a conduta dos homens e das mulheres envolvidos na turbulência da desregulamentação econômica e da conversão da ajuda social em trampolim para o emprego precário. No interior dessa proposta de organização, a prisão assume um papel maior, que se traduz, para os grupos que vivem nas regiões inferiores do espaço social, na imposição de tutela severa e minuciosa. Esta nova política da pobreza foi inventada nos Estados Unidos durante o período que se entende de 1973 a 1996, na trilha da reação social, racial e estatal aos movimentos progressistas da década anterior, e que veio ser um cadinho da revolução neoliberal".
} 
Nova Zelândia, favoráveis ao desmantelamento do Estado providência, concebiam a medida como necessária para estimular o crescimento econômico e a geração de empregos.

Contrariamente, desconsideravam o desrespeito aos direitos trabalhistas e, consequentemente, suas implicações sociais desastrosas, as quais refletiram na ampliação das desigualdades, que se desdobrou na generalização da insegurança social alimentada, nesse caso, pela segregação dos pobres em guetos e desregulamentação das redes de proteção social que foram substituídas, gradativamente, pelos aparelhos repressores do Estado, ou seja, policial e penal (WACQUANT, 2011).

Perseguindo essa chave de análise, as transformações penitenciárias, iniciadas a partir dos anos 1970, foram retiradas por Wacquant dos debates específicos da criminologia e inseridos no centro das discussões contemporâneas da sociologia, numa perspectiva político-econômica, sobretudo no intuito de explicar a ampliação nas taxas de encarceramentos nos Estados Unidos e no Velho Continente, a partir do viés do sistema econômico neoliberal.

0 aparelhamento policial penal, nesse caso, não era um rearranjo em si mesmo ou da manifestação de uma estratégia de controle social, na perspectiva durkheimiana, pelo intermédio da elaboração de regras jurídicas para combater o afrouxamento das normas socialmente estabelecidas e a desobediência a elas. Para Wacquant (2007, 2011), as transformações no modelo de gestão das populações pauperizadas constituem um projeto político econômico neoliberal, o qual encontrou respaldo num especial momento de insegurança salarial e social.

Assim, por meio do entendimento constituído na sociologia política, a sustentação do argumento da nova ordem da política econômica neoliberal forjou a necessidade uma nova razão penal, que se caracterizou pela "supressão do estado econômico, enfraquecimento do estado social, fortalecimento e glorificação do estado penal" (WACQUANT, 2011, p. 25). 0 autor defende a tese de que o afastamento e desmonte do Estado de bem-estar social (welfare state) e a passagem gradativa para um Estado penal compõem uma estratégia de punir e segregar os indesejados, especialmente negros, latinos e pobres em prisões ${ }^{9}$, ou seja, a finalidade seria para além da punição aos criminosos.

A punição torna-se, nesse contexto, um mecanismo viável e necessário para atender a população pobre submetida aos tentáculos da nova ordem econômica. Contudo, os critérios objetivos, demandados pela reorganização neoliberal que os Estados Unidos exportavam rapidamente para outros continentes, conflitam com o modelo e compromissos keynesianos, especialmente com a sua característica mais importante, a do Estado interventor, aquele da

\footnotetext{
9 - Durante os governos Reagan (1981-1989) e W. Bush (1989-1993) ocorreu uma expansão que Wacquant (2011) chamou de "vertical" do sistema ou a hiperinflação carcerária nos Estados Unidos. No período, o investimento no sistema punitivo elevou-se a índices maiores que outros setores estratégicos, como o militar. 0 crescimento da população encarcerada prosseguiu durante o governo Clinton (1993-2001), tornando-se o terceiro maior empregador daquele país e gerou mais de 600 mil empregos no setor.
} 
providência social num período que Wacquant (2011) identifica como pós-fordismo e pós-keynesianismo. Em concomitância ao avanço do Estado que o autor nomeou de neodarwinismo, baseado no afastamento do Leviatã, ou seja, do Estado em relação às responsabilidades coletivas.

Com efeito, em nova era de política econômica, revela-se a função de assepsia social do Estado penal para além dos paradigmas estabelecidos socialmente do crime versus castigo, instituido pelo sistema de justiça criminal, estritamente reduzido a explicações do cumprimento da lei e aos aspectos legais. Esse instrumento político deve ser considerado em diferentes ângulos e possibilidades extrapenais do sistema penitenciário, por exemplo, a ideia de que "o sistema penal contribuiu diretamente para a regulamentação dos segmentos mais baixos do mercado de trabalho" (WACQUANT, 2008).

Na nova ordem, legisladores passam a atribuir características de insubordinação política e social aos pobres, pela via de reformulações legislativas que privilegiam a ordem econômica vigente na criação de "governo da miséria" como propôs Löic Wacquant (2011), ao indicar três caracteristicas político-econômicas do aprisionamento: 1. a regulação do mercado de trabaIho; 2. a exclusão dos grupos étnicos e indesejados; 3 . a população pobre, encarcerada, transforma-se em novo produto no mercado. Assim, os resultados ${ }^{10}$ obtidos com o aprisionamento ultrapassam a clivagem de concepções mais ingênuas sobre as políticas sociais penitenciárias e demonstram como se consolidaram as legislações mais austeras que criminalizaram de maneira gerencial as populações pauperizadas em diferentes continentes (WACQUANT, 2011).

No Brasil, o Mapa do encarceramento: os jovens no Brasil (BRASIL, 2015b) abordou, entre outros aspectos, a inexistência de dados detalhados sobre a informação cor/raça em relatórios sobre o sistema carcerário em âmbito nacional. Uma dificuldade, por exemplo, refere-se à metodologia de coleta de dados, com diferentes perspectivas e pressupostos, em relatorias, levantamentos e pesquisas. Ainda assim, entre os indicadores existentes e publicados, há uma marcada característica de sobrerrepresentação da população jovem e negra nos dados, quando comparada à população brasileira em geral.

Em relação à articulação entre as variáveis "cor/raça" e "faixa etária", por exemplo, os documentos Mapa da violência (WAISELFISZ, 2014) e Vidas perdidas e racismo no Brasil (INSTITUTO

10 - Para Wacquant (2007, p. 20-21, grifos nossos), a adesão ao novo modelo de gestão da segurança pública "ocultava o fato que as sociedades contemporâneas dispõem de pelo menos três estratégias principais para tratar as condições e as condutas que julgam indesejáveis, ofensivas ou ameaçadoras, representadas (i) pela higienização dos lugares de visitação e passagem urbana por meio da construção de alojamentos e programas de emprego e renda mínima, que necessitaria de um reposicionamento do Estado em lidar com os fluxos urbanos; (ii) pela criminalização do morador de rua ao relacioná-lo, e a sua condição de rua, exclusivamente às dependências individuais relacionadas ao abuso de álcool ou drogas; e, por fim, (iii) por rotular os desocupados, os pedintes e todos aqueles que estão à margem da nova ordem econômica como passíveis de delinquência ao ponto desumanizá-los". Nessa direção, as sociedades irão metamorfosear-se de modo a colocar as legislações e os dispositivos jurídicos a serviço das demandas ideológicas do período. 
DE PESQUISA ECONÔMICA APLICADA, 2013) demostraram que o grupo composto por jovens negros está mais sujeito a mortes violentas do que outros segmentos populacionais. Além dos dados alarmantes, citados anteriormente, ambas as pesquisas mostram a relevância da análise que leve em conta a categoria cor/raça para a formulação e avaliação de políticas públicas que considerem a necessidade de superação das desigualdades entre os diferentes grupos étnico raciais da população.

Dentre as reflexões teóricas, oriundas de pesquisas e estudos de referência no Brasil, há que se abordar investigações realizadas sob diferentes perspectivas e propósitos. Pesquisas como as de Adorno (1996) apontaram que mesmo a transição para o regime democrático não superou a produção da desigualdade racial do campo da justiça criminal.

Ademais, pesquisa anterior, realizada com base em dados da Fundação Sistema Estadual de Análise de Dados (Seade), vinculada ao estado de São Paulo, no ano 2000, analisou todos os registros criminais relativos aos crimes de roubos, no estado de São Paulo, entre 1991 e 1998. A constatação foi que réus negros são, proporcionalmente, mais condenados que réus brancos e permanecem, em média, mais tempo presos durante o processo judicial (LIMA; TEIXEIRA; SINHORETTO, 2003).

Mais recentemente, pesquisa coordenada por Jacqueline Sinhoretto, intitulada Desigualdade racial e segurança pública em São Paulo (SINHORETTO; SILVESTRE; SCHLITLER, 2014b), apontou para uma realidade de letalidade policial no território de São Paulo, ao analisar o perfil das vítimas e dos autores, que confirma a seletividade etária e racial em debate. Corroborando a reflexão, vale ressaltar a teoria de coculpabilidade e a seletividade da punição elaborada por Zaffaroni (2010, p. 268), que defende a ideia de culpabilidade pela vulnerabilidade, relacionando a vulnerabilidade individual (predominantemente de cunho social e classe) à seletividade penal. Para ele, a situação de vulnerabilidade ocorre quando o sistema penal, especificamente pela via do direito penal, seleciona determinado sujeito e o utiliza como instrumento para justificar o seu exercício de poder. 0 grau da vulnerabilidade da pessoa ao sistema penal é que determina a ocorrência do ilícito, já que há diversos outros crimes em que o sistema penal não atua.

\section{UM PANORAMA DOS INDICADORES NO BRASIL}

Os indicadores relacionados ao encarceramento predominante de pessoas jovens e negras, revelando aspectos do punitivismo no Brasil em uma escala crescente, ao lado dos dados sobre violência letal que incide sobre esse mesmo público, têm explicitado um panorama de seletividade etária, social e racial de um sistema punitivo altamente seletivo, quando comparamos, por exemplo, com os dados nacionais e internacionais.

Trata-se de indicadores presentes em levantamentos e dados sistematizados em pesquisas e/ou oriundos de relatorias, elaborados por pesquisadores, instituições públicas, governamentais 
ou do terceiro setor, disponibilizados gratuita e livremente, sobretudo em formato virtual, e que traremos para a presente discussão. Em relação ao encarceramento em massa, o crescente aumento do aprisionamento de pessoas no Brasil tem como principal alvo jovens negros moradores de setores populares, demonstrando essa seletividade etária, social e racial nos indicadores, além do crescimento acelerado nas últimas décadas de mulheres presas - fenômeno vinculado, entre outros aspectos, à maior participação feminina no tráfico de drogas.

Esse aumento vem sendo justificado, por diversos segmentos, como resposta ao suposto crescimento da criminalidade violenta, do crime organizado, sobretudo, do tráfico de drogas ilícitas, e de conflitos sociais de diversas ordens, em sua grande parte decorrente das exponenciais desigualdades sociais que impactam o acesso a direitos básicos no país, ao lado de uma postura de inflexão, em geral, do Estado, em relação às políticas públicas.

0 balanço desses aprisionamentos indica que 37\% dos privados de liberdade estão reclusos via o dispositivo da prisão preventiva, o qual se apresenta como instrumento jurídico eficaz para a manutenção de parcela da população presa. Como demonstrado, a clientela carcerária é constituída, em sua maioria, por homens negros jovens, moradores de regiões periféricas e que já se encontravam excluídos anteriormente das demandas de consumo e com pouco acesso às políticas sociais. 0 Departamento Penitenciário Nacional $(2015$, p. 6) reconhece que a maior parcela de encarcerados no Brasil é formada "majoritariamente de jovens negros, de baixa escolaridade e de baixa renda".

Os dados publicados em 2017 pelo Departamento Penitenciário Nacional, por meio do relatório do Levantamento Nacional de Informações Penitenciárias (BRASIL, 2017), evidenciam que 40\% dos mais de 726 mil indivíduos privados de liberdade no sistema prisional ${ }^{11}$ são presos provisórios. Outros 30\% têm entre 18 e 24 anos $^{12}$; 25\%, entre 25 e 29; e 19\%, 30 e 34 anos.

Pode-se afirmar, com base nas informações disponibilizadas, que 74\% dos privados de liberdade são jovens e 64\% são negros, e 87\% têm até o ensino fundamental incompleto e apenas 9\% concluíram o ensino médio. Os dados expressam a avassaladora seletividade prisional da população jovem, uma vez que no Brasil a população está concentrada na faixa de idade abaixo dos 35 anos.

0 comparativo dos indicadores carcerários em relação à população em geral demonstra a seletividade penal, visto que, em média, 53,6\% da população brasileira é negra e 32\%

11 - Esse dado pode ser ainda mais grave, considerando-se que o levantamento é referente ao mês de junho de 2016 e, ainda, estão fora dele as pessoas detidas em delegacias e carceragens, e que a população é "flutuante", com entradas e saidas variadas em um ano de análise.

12 - Trata-se de um público, portanto, jovem, tomando como referência o preconizado pelas políticas públicas para a juventude, para pessoas de 15 até 29 anos, e o Estatuto da Juventude, instituido pela Lei Federal n. 12.852, de 5 de agosto de 2013. 
apresentam ensino médio completo, enquanto a população prisional representa apenas 9\% (BRASIL, 2017).

No mesmo sentido, o Mapa do encarceramento: os jovens do Brasil (BRASIL, 2015b, p. 33), ao identificar a escassez de estudos que relacionam o crescimento da população prisional com a informação cor/ raça dos presos, propõe-se a responder à necessidade de estudos dessa natureza, além de elaborar um diagnóstico da questão racial entre a população prisional.

Diante dos dados sobre cor/raça verifica-se que, em todo o periodo analisado, existiram mais negros presos no Brasil do que brancos. Em números absolutos: em 2005 havia 92.052 negros presos e 62.569 brancos, ou seja, considerando-se a parcela da população carcerária para a qual havia informação sobre cor disponivel, 58,4\% era negra. Já em 2012 havia 292.242 negros presos e 175.536 brancos, ou seja, 60,8\% da população prisional era negra. Constata-se assim que quanto mais cresce a população prisional no pais, mais cresce 0 número de negros encarcerados. 0 crescimento do encarceramento é mais impulsionado pela prisão de pessoas negras do que brancas. Note-se também o crescimento paulatino da categoria outras, utilizada pelos gestores do sistema penitenciário que preenchem os relatórios encaminhados ao INFOPEN. A utilização desta categoria cresceu oito vezes no período analisado, o que compromete a qualidade do dado fornecido e pode prejudicar a consistência das análises do quadro apresentado.

[...]

Para ter a dimensão mais precisa da seletividade racial no sistema prisional brasileiro, é necessário fazer uma ponderação pela taxa de encarceramento segundo grupos de cor/ raça; ou seja, uma análise do número de presos negros e brancos de acordo com o número de habitantes negros e brancos. Considerando-se os dados do INFOPEN sobre a população no período de 2005 a 2012 e as estimativas para a população brasileira acima de 18 anos no mesmo período, segundo brancos e negros, é possivel observar que o encarceramento de negros aumentou mais do que o encarceramento de brancos. Em 2012, para cada grupo de 100 mil habitantes brancos acima de 18 anos havia 191 brancos encarcerados, enquanto para cada grupo de 100 mil habitantes negros acima de 18 anos havia 292 negros encarcerados, ou seja, proporcionalmente o encarceramento de negros foi 1,5 vez maior do que o de brancos em 2012 (BRASIL, 2015a, p. 33, grifo do autor).

Nesse contexto, partindo-se dos principais indicadores e dados sistematizados e divulgados sobre o tema, o Grupo de Trabalho das Nações Unidas sobre Detenção Arbitrária ${ }^{13}$, em 2013, em visita ao Brasil, criticou a excessiva privação da liberdade como principal resposta

13 - Informações disponíveis em: <https://nacoesunidas.org/grupo-de-trabalho-sobre-detencao-arbitraria-declaracao-aposa-conclusao-de-sua-visita-ao-bra- sil-18-a-28-marco-de-2013>. Acesso em: 21 ago. 2016. 
punitiva, identificando um tratamento desigual do sistema de justiça penal contra populações negras e pobres. Essa desigualdade de tratamento associa-se ao fenômeno chamado genocídio da juventude negra, com viés racista e recorte etário e social, discutido por pesquisadores e denunciado por movimentos sociais e sociedade civil organizada ${ }^{14}$.

Vale ressaltar, nessa discussão, que, apesar de partirem de concepções, objetivos e marcos normativos distintos, na prática, o sistema de medidas socioeducativas de responsabilização de adolescentes por atos infracionais e o sistema prisional brasileiro possuem semelhanças, ao incidirem de modo preponderante na população jovem, negra e periférica, que vivencia, em geral, processos de socialização incompleta (ADORNO, 1991).

Há, portanto, uma tendência de práticas punitivas nos mesmos moldes para o público adolescente e adulto, a despeito do que preconiza e institui, por exemplo, o Estatuto da Criança e do Adolescente, instituído pela Lei Federal n. 8.069/1990. Integram, assim, um mesmo locus, modelo de atuação e sentido dos sistemas penal, prisional e socioeducativo brasileiro para com a juventude.

No que se refere à violência letal, especialmente ao risco de morte dos adolescentes negros, em razão de homicídio, de acordo com dados do Programa de Redução da Violência Letal contra Adolescentes e Jovens (BRASIL, 2014) para a população de todos os municípios com mais de 100 mil habitantes em 2012, os adolescentes negros vivem um risco 2,96 maior de serem assassinados do que os brancos, revelando uma significativa desigualdade racial. A maior parte dos municipios (51\%) apresentou valor entre um e cinco, ou seja, o risco de um adolescente negro ser vítima de homicidio chega a ser cinco vezes maior que o dos adolescentes brancos.

Nesse sentido, em 2015, foi instalada, no Senado, uma Comissão Parlamentar de Inquérito (CPI) sobre o Assassinato de Jovens ${ }^{15}$, com a realização de 29 audiências públicas em vários estados brasileiros, além do levantamento de dados nas Secretarias de Segurança Pública estaduais. De acordo com dados apurados pelo colegiado, o homicídio continua sendo a principal causa de morte de jovens negros, pobres e moradores da periferia no país.

A CPI concluiu que há um "genocídio simbólico" contra jovens negros no Brasil e denunciou a escassez de serviços públicos básicos nas localidades onde a maior parte da população é negra e pobre. Além disso, outro tema de destaque foi a desigualdade entre brancos e negros na abordagem praticada pelas polícias.

\footnotetext{
14 - Segundo a organização não governamental Geledés - Instituto da Mulher Negra, "o signo genocídio surgiu da junção da palavra grega génos que significa raça, povo, tribo ou nação e da palavra latina caedere que quer dizer destruição, aniquilamento, ruina ou matança. Assim, genocídio quer significar a destruição de uma raça". Genocídio da juventude negra, por sua vez, é uma expressão utilizada para designar crimes que têm como objetivo a eliminação da existência física de grupos étnico-raciais. Disponivel em: <http://www.geledes.org.br/o-genocidio-da-juventude-negra-no-brasil/>. Acesso em: 22 ago. 2016.

15 - Disponivel em: <http://www12.senado.leg.br/noticias/materias/2016/06/08/em-relatorio-cpi-apresenta-sugestoes-paraacabar-com-genocidio-da-ju- ventude-negra>. Acesso em: 22 ago. 2016.
} 
Vale ressaltar que o relatório final da $\mathrm{CPI}^{16}$, com base em diversos indicadores, relatos e levantamentos, além de abordagens sobre o racismo estrutural no Brasil, apresenta argumentos imprescindiveis para o debate sobre o genocídio da população negra, homicídios decorrentes de ação policial, violência contra a juventude no Brasil, bem como recomendações e proposições legislativas para enfrentamento a esse cenário de violências.

Esse último problema foi analisado em publicação do Instituto de Pesquisa Econômica Aplicada (Ipea), um estudo intitulado Violência letal no Brasil e vitimização da população negra: qual tem sido o papel das polícias e do Estado? (OLIVEIRA JUNIOR; LIMA, 2013). A desigualdade citada é confirmada pela chance 3,7 vezes maior de um adolescente negro ser vítima de homicídio, se comparado a um adolescente branco (OLIVEIRA JUNIOR; LIMA, 2013). 0 Ipea, também em 2013, publicou nota técnica denominada Vidas perdidas e racismo no Brasil, explicitando, entre outros aspectos, que a letalidade violenta é uma pesada herança das discriminações econômicas e raciais contra os afrodescendentes no Brasil (IPEA, 2013). Em termos proporcionais, e analisando a população em geral, para cada homicídio de um individuo não negro no Brasil, 2,4 negros são assassinados, em média.

Ainda em relação à CPI, o parecer final aprovado no dia 15 de julho de $2016^{17}$ traz, por exemplo, números do Sistema de Informação de Mortalidade do Ministério da Saúde (SIM/ Datasus): entre 2008 e 2011, houve 206 mil homicídios no país - média de 141 por dia. No ano de 2011, por exemplo, verifica-se que mais da metade dos 52 mil mortos por homicídio eram jovens (53,3\%), dos quais 71,44\% eram negros, e 93,03\%, homens. Como medidas urgentes, 0 texto final da CPI recomenda a aprovação de projetos de lei, emenda à Constituição Federal de 1988 e resoluções, que preveem, por exemplo, a criação de um plano nacional de enfrentamento ao homicídio de jovens e de um fundo nacional para superação do racismo.

Diante disso, o relatório final ${ }^{18}$ indica três principais ações: 1. um Plano Nacional de Redução de Homicídios de Jovens ${ }^{19}{ }^{2}$ 2. transparência de dados sobre segurança pública e violência e 3. fim dos autos de resistência (termo utilizado por policiais que alegam estar se defendendo ao matar um suspeito). Ademais, a desmilitarização da polícia e alterações na organização dos órgãos de segurança pública, com vistas a um maior controle da atividade policial, são recomendações do documento.

16 - Disponivel em: <https://www12.senado.leg.br/noticias/arquivos/2016/06/08/veja-a-integra-do-relatorio-da-cpi-doassassinato-de-jovens>. Acesso em: 19 fev 2018.

17 - Disponivel em: <http://migre.me/wu8uC>. Acesso em: 22 ago. 2016.

18 - 0 relatório final na integra está disponivel: <http://migre.me/wu8vl>. Acesso em: 22 ago. 2016.

19 - A esse respeito, destaca-se, ainda, que no início do ano de 2018 foi proposto um Plano Nacional de Enfrentamento ao Homicídio de Jovens aprovado pela Comissão de Constituição e Justiça do Senado, visando enfrentar os altos índices apresentados de violência letal contra jovens negros e pobres. Ainda está em tramitação. Mais informações estão disponiveis em: $<$ http://agenciabrasil.ebc.com.br/politica/noticia/2018-02/senado-quer-urgencia-para-plano-de-enfrentamento-ao-homicidiode-jovens>. Acesso em: 9 mar. 2018. 
Importante documento que apresenta indicadores relacionados à temática trata-se do, já citado, Mapa da violência, que compõe um conjunto de estudos desenvolvidos desde 1998, publicado pela Organização das Nações Unidas para a Educação, a Ciência e a Cultura (Unesco) e Faculdade Latino-Americana de Ciências Sociais (Flacso) ${ }^{20}$. No ano de 2014, o Mapa da violência: os jovens do Brasil (WAISELFISZ, 2014) apresentou a taxa de assassinato de jovens brancos e negros no Brasil, conforme demonstrado no mapa a seguir.

Figura 1 Assassinato de jovens no Brasil

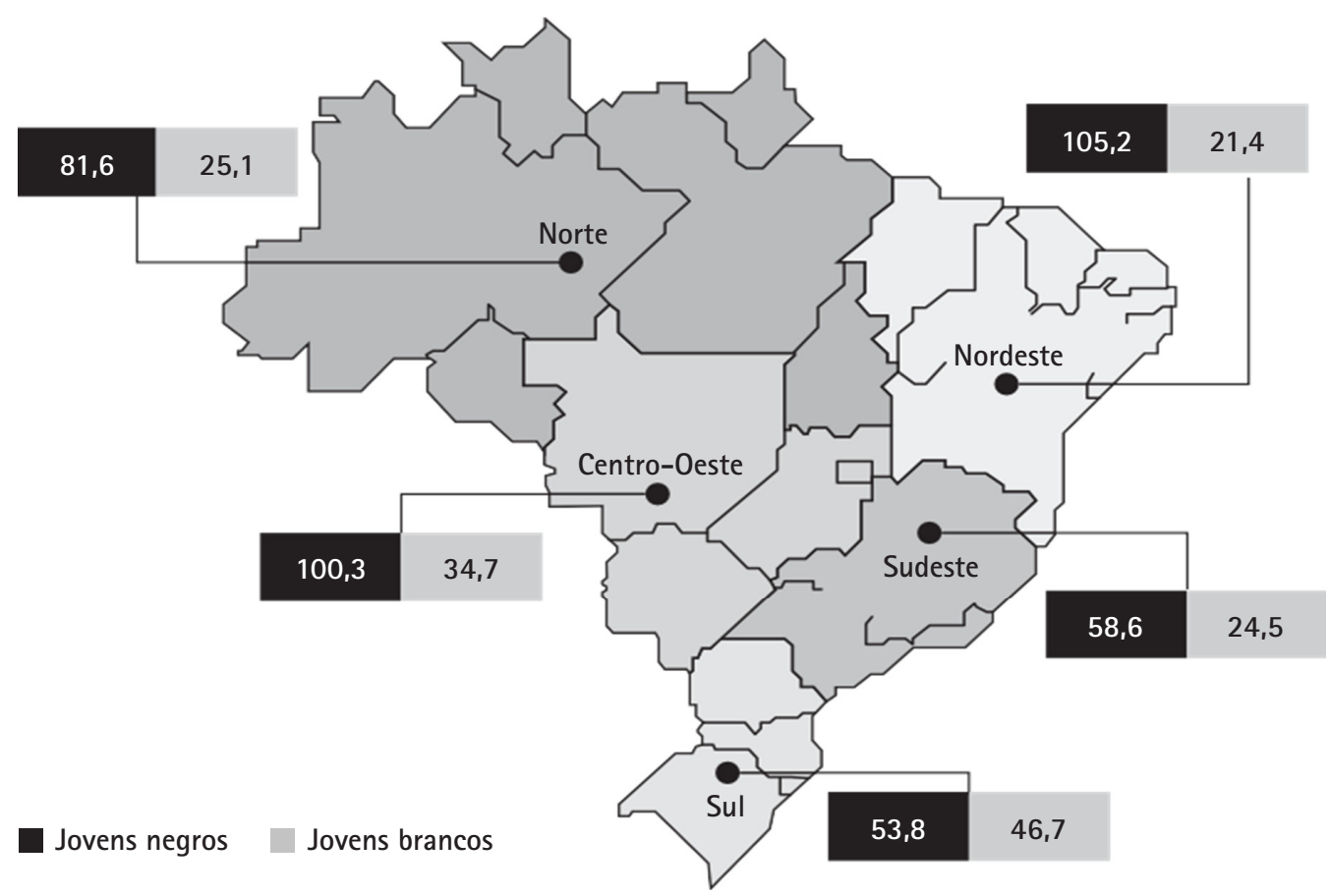

Fonte: Waiselfisz (2014).

No ano de 2016, o Mapa da violência trata dos homicídios por armas de fogo e de suas variáveis no Brasil (WAISELFISZ, 2016). No panorama internacional, o Brasil ocupa a décima posição entre os 100 países analisados, com taxa de 20,7 homicídios por arma de fogo por cada 100 mil habitantes.

Especificamente ao tratar sobre a idade e a cor das vitimas, apresenta dados alarmantes: como constatado desde o primeiro Mapa da violência, divulgado em 1998, a principal vítima da violência homicida no Brasil é a juventude. Na faixa de 15 a 29 anos de idade, o crescimento da letalidade violenta foi bem mais intenso do que no resto da população. No conjunto da 
população, de 1980 a 2014 houve um crescimento de 592,8\%, enquanto na faixa jovem esse crescimento foi de 699,5\% (WAISELFISZ, 2016, p. 49-60).

No mesmo período, morreram no Brasil 967.851 vítimas de disparo de arma de fogo, contudo o número de negros assassinados é duas vezes maior em relação aos vitimados da cor branca. 0 mapa explicita, assim, o crescimento das taxas de homicídios por armas de fogos contra negros e a redução em relação à população branca: entre 2003 e 2014, as taxas de homicídios por armas de fogos de brancos caem 27,1\%, de 14,5\%, em 2003, para 10,6\%, em 2014; enquanto a taxa de homicídios de negros aumenta 9,9\% de 24,9 para 27,4\%. Com esse diferencial, a vitimização negra do país, que em 2003 era de 71,7\%, em poucos anos mais que duplica: em 2014, já é de 158,9\%, ou seja, morrem 2,6 vezes mais negros que brancos vitimados por arma de fogo.

No ano de 2003, por exemplo, foram cometidos 13.224 homicídios por arma de fogo na população branca, em 2014 esse número diminui para 9.766, o que representa uma queda de 26,1\%. Em contrapartida, o número de vítimas negras passa de 20.291 para 29.813, com aumento de 46,9\%. Assim, "a vitimização negra no país que, em 2003, era de 71,7\% (morrem, proporcionalmente, 71,7\% mais negros que brancos), pula para 158,9\%, em 2014" (WAISELFISZ, 2016, p. 60).

0 Atlas da violência 2017, lançado pelo Ipea e pelo Fórum Brasileiro de Segurança Pública (FBSP), reafirma que homens, jovens, negros e de baixa escolaridade são as principais vítimas de mortes violentas no Brasil. A população negra corresponde à maioria (78,9\%) dos 10\% dos indivíduos com mais chances de ser vítimas de homicídios. Atualmente, de cada 100 pessoas assassinadas no Brasil, 71 são negras. De acordo com o Atlas, os negros possuem 23,5\% chances maiores de ser assassinados em relação a brasileiros de outras raças.

\section{NOTAS FINAIS}

0 endurecimento de práticas recorrentes na área da segurança pública e justiça criminal, identificada nos indicadores e nas pesquisas, explicita a tendência de criminalizar um possível "grupo de risco", via uma política-polícia-criminal, que amplia, progressivamente, a vigilância e a aplicação das legislações punitivas e de violência letal em relação à juventude negra no Brasil, notadamente moradores de periferias.

Verifica-se a ampliação dos tentáculos do Estado repressor via os mecanismos de segurança pública, fato que ocasiona um olhar punitivo, de suspeição, encarceramento e/ou extermínio de grande parcela dos moradores das regiões periféricas, dentre eles, jovens negros, sob a aparência de um mecanismo que compreendido como eficaz para instituir a "lei e a ordem" em localidades e pessoas consideradas perigosas. Há a assunção de um "inimigo" social e racialmente definido como indesejável. 
A partir daí observa-se que a emergência por alternativas de "punir melhor", e cada vez mais, elevou a população pobre e, em especial, a negra ao patamar de prováveis delinquentes. Isso significa afirmar que os mecanismos de justiça e segurança pública agregam, ao olhar e à prática punitiva e violenta, fatores que interseccionam classe, raça e idade, sobretudo em crimes relacionados ao patrimônio e à política de drogas no Brasil.

Os indicadores e as pesquisas sobre o tema deixam evidente que a predominância da suspeição criminal, a punição, o encarceramento e a violência letal ocorrem, principalmente, contra os jovens negros, pobres e moradores em regiões periféricas no Brasil. É preciso considerar que pessoas estão sendo verdadeiramente silenciadas e/ou exterminadas da sociedade, em nome de uma "segurança pública" ou "punição" a qualquer custo. Esse ato demonstra a intencionalidade subjetiva do Estado de punir os "indesejados da cidade", ou seja, aqueles individuos caracterizados pelo baixo poder de consumo, moradores de regiões periféricas e afrodescendentes.

A postura de inflexão por parte do Estado, tanto no atendimento dos direitos e garantias constitucionais, via políticas públicas quanto na oferta de segurança pública preventiva e na promoção de direitos e cidadania, por meio de políticas públicas a todos, favorece a vulnerabilidade da população pobre e marginalizada socialmente e fortalece mecanismos de atuação de um Estado penal. Quando o essencial, na atual conjuntura, seria o Estado promover política pública de segurança, sim, mas na direção de desmitificar o crime e a criminalidade violenta no Brasil.

Nesse sentido, uma das análises possiveis, com base no panorama de indicadores apresentado, é que o sistema de punição, operado por instituições e atores ligados à área da segurança pública e justiça criminal, tem sido marcado por resultados com viés racial, na direção de institucionalização implícita de uma prática de racismo Estatal, que atua de modo seletivo, a partir de práticas de controle, neutralização, punitivismo, encarceramento e genocídio da juventude negra.

\section{Black lives: an overview of social selectivity, incarceration and homicide of black youth in Brazil}

Abstract: This article aims to discuss the imprisonment of black youth in Brazil. Initially, based on a bibliographical
survey and the main indicators available, it presents the panorama of homicide and incarceration of young blacks
in the country, and then discuss how the mechanisms of social selectivity operate on this stratum of the popu-
lation with, in particular, age and race. Among the results found, it is emphasized that the identification of a
supposed "risk group," the expansion of the imprisonment and the extermination of black people, are socially
reified and are visibly intertwined with a process of criminalization of the popular strata living in peripheral
regions. Based on these assumptions, the analysis elucidates reflective clues about how the social cataloging of 
these men and women, constituted a priori in the collective unconscious impact on the systematic practices of the criminal justice system and its operators, have decisively impacted on life trajectories and, in the application of criminal law. It may be noted that data from the most recent prison population as well as indicators of lethal violence point to an overrepresentation of the young and black public, which leads us to reflect on a scenario that has been termed by experts as "genocide of youth black" in Brazil, without there is a specific policy to confront these systematic practices.

Keywords: Incarceration. Black youth. Homicide. Violence. Criminalization of poverty.

\section{REFERÊNCIAS}

ADORNO, S. A socialização incompleta: os jovens delinquentes expulsos da escola. Cadernos de Pesquisa, São Paulo, v. 79, p. 76-80, 1991.

ADORNO, S. Racismo, criminalidade violenta e justiça penal: réus brancos e negros em perspectiva comparativa. Estudos Históricos, Rio de Janeiro, v. 9, n. 18, p. 283-300, 1996.

ALVAREZ, M. C.; SALLA, F.; DIAS, C. C. N. Das comissões de solidariedade ao Primeiro Comando da Capital em São Paulo. Tempo Social, São Paulo, v. 25, n. 1, 2013.

BITENCOURT, C. R. Falência da pena de prisão: causas e alternativas. São Paulo: Saraiva, 2017. BRASIL. Constituição (1988). Constituição da República Federativa do Brasil de 1988. Diário Oficial da União, Brasilia, DF, 5 out. 1988. Disponivel em: <http://www.planalto.gov.br/ccivil_ 03/constituicao/constituicaocompilado.htm>. Acesso em 20 jul. 2017.

BRASIL. Lei n. 13.675, de 11 de junho de 2018. Disciplina a organização e o funcionamento dos órgãos responsáveis pela segurança pública, nos termos do $\S 7^{\circ}$ do art. 144 da Constituição Federal; cria a Política Nacional de Segurança Pública e Defesa Social (PNSPDS); institui o Sistema Único de Segurança Pública (Susp); altera a Lei Complementar n 79, de 7 de janeiro de 1994, a Lei no 10.201, de 14 de fevereiro de 2001, e a Lei no 11.530, de 24 de outubro de 2007; e revoga dispositivos da Lei no 12.681, de 4 de julho de 2012. Diário Oficial da União, Brasilia, DF, 11 jun. 2018. Disponivel em: <http://www.planalto.gov.br/ccivil_03/_ato20152018/2018/lei/L13675.htm>. Acesso em: 5 out. 2018.

BRASIL. Ministério da Justiça. Departamento Penitenciário Nacional (Depen). Levantamento Nacional de Informações Penitenciárias INFOPEN - Junho de 2014. Infopen, 2015a. Disponível em: <http://www.justica.gov.br/news/mj-divulgara-novo-relatorio-do-infopen-nestaterca-feira/relatorio-depen-versao-web.pdf>. Acesso em: 14 jun. 2016.

BRASIL. Ministério da Justiça. Departamento Penitenciário Nacional (Depen). Levantamento Nacional de Informações Penitenciárias - Atualização - Junho de 2016. Infopen, 2017. Disponivel em: <http://www.justica.gov.br/news/ha-726-712-pessoas-presas-no-brasil/relatorio_ 2016_junho.pdf>. Acesso em: 30 jan. 2018. 
BRASIL. Presidência da República. Secretaria Geral da Presidência da República. Secretaria Nacional da Juventude. Mapa do encarceramento: os jovens do Brasil. Brasilia: Presidência da República, 2015b. Disponível em: <http://www.pnud.org.br/arquivos/encarceramento_ WEB.pdf>. Acesso em: 22 ago. 2016.

BRASIL. Secretaria de Direitos Humanos da Presidência da República. Programa de Redução da Violência Letal contra Adolescentes e Jovens. Homicidios na adolescência no Brasil IHA 2012. 2014. Disponivel em: <http://prvl.org.br/wp-content/uploa-ds/2015/01/IHA_2012. pdf>. Acesso em: 23 ago. 2016.

CALDEIRA, T. P. do R. Violência, direitos e cidadania: relações paradoxais. Ciência e Cultura, Campinas, v. 54, n. 1, p. 44-46, 2002.

CAMPOS, M. da S. Drogas e prisões no centro da cidade de São Paulo. In: TORRES, E.; MACIEL, G. (Orgs.). Prisões, violência e sociedade: debates contemporâneos. São Paulo: Paco, 2017.

CARVALHO, S.; CARVALHO, A. B. de. Aplicação da pena e garantismo. 2. ed. Rio de Janeiro: Lumen Juris, 2002.

DIAS, C. C. N. PCC: hegemonia nas prisões e monopólio da violência. São Paulo: Saraiva, 2013.

FLAUZINA, A. P. Corpo negro caído no chão: o sistema penal e o projeto genocida do Estado brasileiro. 2006. Dissertação (Mestrado em Direito) - Universidade de Brasilia, Brasília, 2006.

GARLAND, D. The culture of control: crime and social order in contemporary society. Chicago: University of Chicago Press, 2001.

INSTITUTO DE PESOUISA ECONÔMICA APLICADA. Vidas perdidas e racismo no Brasil. Brasília: Ipea, 2013. Disponivel em: <http://www.ipea.gov.br/portal/images/stories/PDFs/nota_tecnica/ 131119_notatecnicadiest10.pdf>. Acesso em: 29 ago. 2016.

INSTITUTO DE PESOUISA ECONÔMICA APLICADA. Mapa da violência: homicídios e juventude no Brasil. Brasilia: Ipea, 2014a. Disponivel em: <https://www.mapadaviolencia.org.br/pdf2014/ Mapa2014_AtualizacaoHomicidios.pdf>. Acesso em: 13 jul. 2016.

INSTITUTO DE PESOUISA ECONÔMICA APLICADA. Mapa da violência: jovens do Brasil. Brasília: Ipea, 2014b. Disponivel em: <http://www.mapadaviolencia.org.br/pdf2014/Mapa2014_ JovensBrasil_Preliminar.pdf>. Acesso em: 13 mar. 2016.

INSTITUTO DE PESQUISA ECONÔMICA APLICADA. Atlas da violência 2017. Brasília: Ipea, 2017. Disponivel em: <http://www.ipea.gov.br/atlasviolencia/download/2/2017>. Acesso em: 18 jan. 2018.

LIMA, R. S. de; TEIXEIRA, A.; SINHORETTO, J. Raça e gênero no funcionamento da justiça criminal. Boletim IBCCrim, São Paulo, n. 125, abr. 2003. 
LOPES, R. E. et al. Juventude pobre, violência e cidadania. Saúde e Sociedade, São Paulo, v. 17. n. 3, p. 63-76, set. 2008.

MARQUES, A. Crime, proceder, convívio-seguro: um experimento antropológico a partir de relações entre ladrões. 2009. Dissertação (Mestrado em Antropologia Social) - Universidade de São Paulo, São Paulo, 2009.

OLIVEIRA JUNIOR, A. de; LIMA, V. C. de A. Violência letal no Brasil e vitimização da população negra: qual tem sido o papel das polícias e do Estado? In: SILVA, T. D.; GOES, F. L. Igualdade racial no Brasil: reflexões no ano internacional dos afrodescentes. Rio de Janeiro: Ipea, 2013. p. 121-134. Disponivel em: <http://www.ipea.gov.br/portal/images/stories/PDFs/livros/livros/ livro_igualdade_racialbrasil01.pdf>. Acesso: 10 ago. 2017.

PINHEIRO, P. S. Crime, violência e poder. São Paulo: Brasiliense, 1983.

RAMALHO, J. R. O mundo do crime: a ordem pelo avesso. Rio de Janeiro: Graal, 1979.

SALLA, F. As rebeliões nas prisões: novos significados a partir da experiência brasileira. Sociologias, Porto Alegre, v. 8, n. 16, p. 274-307, 2006. Disponivel em: <http://www.scielo.br/pdf/ soc/n16/a11n16.pdf>. Acesso: 21 maio 2017.

SINHORETTO, J.; SILVESTRE, G.; MELO, F. A. L. de. O encarceramento em massa em São Paulo. Tempo Social, São Paulo, v. 25, n. 1, p. 83-106, 2013.

SINHORETTO, J.; SILVESTRE, G.; SCHLITTLER, M. C. A produção da desigualdade racial na segurança pública de São Paulo. In: REUNIÃO BRASILEIRA DE ANTROPOLOGIA, 29., 2014, Natal. Natal,2014a.Disponivelem:<http://www.29rba.abant.org.br/resources/anais/1/1402023218_ ARQUIVO_Paper_ABA2014_Schlittler_Silvestre_Sinhoretto.pdf >. Acesso em: 15 set. 2016.

SINHORETTO, J.; SILVESTRE, G.; SCHLITTLER, M. C. Desigualdade racial e segurança pública em São Paulo: letalidade policial e prisões em flagrante. São Carlos: UFSCar, 2014b. Disponível em: <http://www.ufscar.br/gevac/wp-content/uploads/Sum\%C3\%A1rio-Executivo_FINAL_ 01.04.2014a. pdf>. Acesso em: 22 ago. 2016.

TORRES, E. N. A gênese da remição de pena pelo estudo: o dispositivo jurídico-político e a garantia de privados de liberdade no Brasil. 2017. Tese (Doutorado em Educação) - Universidade Estadual de Campinas, Campinas, 2017.

WACQUANT, L. Punir os pobres: a nova gestão da miséria nos Estados Unidos [A onda punitiva]. Tradução Sérgio Lamarão. 3. ed. Rio de Janeiro: Revan, 2007.

WACQUANT, L. O lugar da prisão na nova administração da pobreza. Tradução Paula Miragla e Hélio de Mello Filho. Novos Estudos, São Paulo, v. 80, p. 9-19, mar. 2008.

WACQUANT, L. As prisões da miséria. Tradução André Telles. 2. ed. Rio de Janeiro: Jorge Zahar, 2011. 
WAISELFISZ, J. J. Mapa da violência 2012: a cor dos homicídios no Brasil. Rio de Janeiro: Cebela; Brasilia: Flacso; Curitiba: Seppir/PR, 2012.

WAISELFISZ, J. J. Mapa da violência 2014: os jovens do Brasil. Rio de Janeiro: Cebela; Brasília: Flacso; Curitiba: Seppir/PR, 2014.

WAISELFISZ, J. J. Mapa da violência 2015: mortes matadas por armas de fogo. Brasília: Flacso, 2015. Disponivel em: <http://www. mapadaviolencia.org.br/pdf2015/mapaViolencia2015. pdf>. Acesso em: 15 set. 2016.

WAISELFISZ, J. J. Mapa da violência no Brasil: homicídios por armas de fogo. Brasilia: Flacso, 2016. Disponível em: <http://www.mapadaviolencia.org.br/pdf2016/Mapa2016_armas_web. pdf>. Acesso em: 27 ago. 2016.

ZAFFARONI, E. R. Em busca das penas perdidas: a perda da legitimidade do sistema penal. 5. ed. Rio de Janeiro: Revan, 2010.

ZAFFARONI, E. R.; PIRANGELLI, J. H. Manual de direito penal brasileiro: parte geral. São Paulo: Revista dos Tribunais, 1997. 